\title{
RETRACTION $\square$
}

\section{Retraction:}

\section{Pleural Cryptococcosis with Idiopathic CD4 Positive T-lymphocytopenia}

[Internal Medicine 43 (10): 977, 2004]

Takashi KAWABATA, Wataru MATSUYAMA, Ikkou HIGASHIMOTO,

Yoshifusa KOREEDA, Nobutaka EIRAKU, Masaharu KAWABATA and Mitsuhiro OSAME

Third Department of Internal Medicine, Kagoshima University Faculty of Medicine

This paper was withdrawn by the authors due to the inclusion of incorrect experimental data.

Internal Medicine Vol. 47: 1765, 2008

DOI: 10.2169/internalmedicine.47.R002 


\title{
Pleural Cryptococcosis with Idiopathic CD4 Positive T-lymphocytopenia
}

\author{
Takashi Kawabata, Wataru Matsuyama, Ikkou Higashimoto, Yoshifusa KoreEdA, \\ Nobutaka EIRAKU, Masaharu KAWABATA and Mitsuhiro OSAME
}

\begin{abstract}
A 19-year-old man was admitted to our hospital because of chest pain. He was diagnosed as having pleural cryptococcosis by pleural biopsy. His CD4 positive Tlymphocyte count was low $(<300 \mu \mathrm{l})$ and there was no evidence of human immunodeficiency virus infection. He was successfully treated with fluconazole. However, his CD4 positive lymphocyte counts remained low after the recovery and he was diagnosed as idiopathic CD4 positive T-lymphocytopenia. Pleural cryptococcosis is rare and its predisposing condition is still controversial. To our knowledge, this is the first case of pleural cryptococcosis associated with idiopathic CD4 positive $T$ lymphocytopenia.

(Internal Medicine 43: 977-981, 2004)
\end{abstract}

Key words: CD4 lymphocytes, Cryptococcus neoformans, CD95 (Fas/Apo-1)

\section{Introduction}

The most common manifestation of Cryptococcus neoformans infection is meningitis followed by pulmonary involvement (1). Among pulmonary infections, pleural cryptococcosis is extremely rare, and, for the early diagnosis, it is important to pay attention to immuno-deficientive status such as acquired immuno-deficiency syndrome (AIDS) (2).

On the other hand, idiopathic CD4 positive T-lymphocytopenia (ICL) is a recently described syndrome characterized by a significant depression in the number of circulating CD4 positive T-lymphocytes in the absence of human immuno-deficiency virus (HIV) infection (3). ICL causes some opportunistic infections including Cryptococcus neoformans (4). However, there has been no report of pleural cryptococcosis associated with ICL. Here, we report the first case of pleural cryptococcosis associated with ICL. We propose that ICL can become one of the predisposing conditions of pleural cryptococcosis.

\section{Case Report}

A 19-year-old man was admitted to our hospital because of chest pain. One month before admission, he developed left sided chest pain. Two weeks before admission, he went to another hospital. A chest X-ray film and chest computed tomography (CT) showed thickness of left pleura. He was treated with some antibiotics (piperacillin, minocycline and imipenem) with unsuccessful results. His chest pain persisted and he was admitted to our hospital. He had been in good health except for appendicitis 3 years before admission, and had never traveled abroad nor abused drugs. He had smoked a pack of cigarettes per day for 2 years.

Laboratory findings on admission showed leukocytopenia (white blood cell counts was 2,980/ $\mu$ and CD4+ lymphocyte counts was $292 / \mu \mathrm{l})$. The amount of pleural effusion was too small to aspirate for laboratory tests. Natural killer cell activity was normal and serum immunoglobulin levels were in normal range. Lymphocyte blastogenesis against PHA was normal range. Purified derivative tuberculin skin test was negative. The antibodies for HIV and human T-lymphotrophic virus type-I (HTLV-I) were negative in serum. Cryptococcus antigen was negative in blood and in cerebrospinal fluid. Cultures of his sputum, blood, urine and cerebrospinal fluid were all negative for fungi. Chest CT still showed left pleural thickness (Fig. 1). Thoracoscopic pleural biopsy was performed for a definitive diagnosis. The biopsy specimen revealed pleural thickness with numerous infiltrates that was identified as budding encapsulated yeast forms, compatible with cryptococcus, and some inflammatory cells (Fig. 2). The diagnosis of pleural cryptococcosis was made and anti-fungal therapy was begun (fluconazole

From the Third Department of Internal Medicine, Kagoshima University Faculty of Medicine, Kagoshima

Received for publication December 4, 2003; Revised for publication June 8, 2004

Reprint requests should be addressed to Dr. Wataru Matsuyama, the Third Department of Internal Medicine, Kagoshima University Faculty of Medicine, Sakuragaoka 8-35-1, Kagoshima 890-8520 

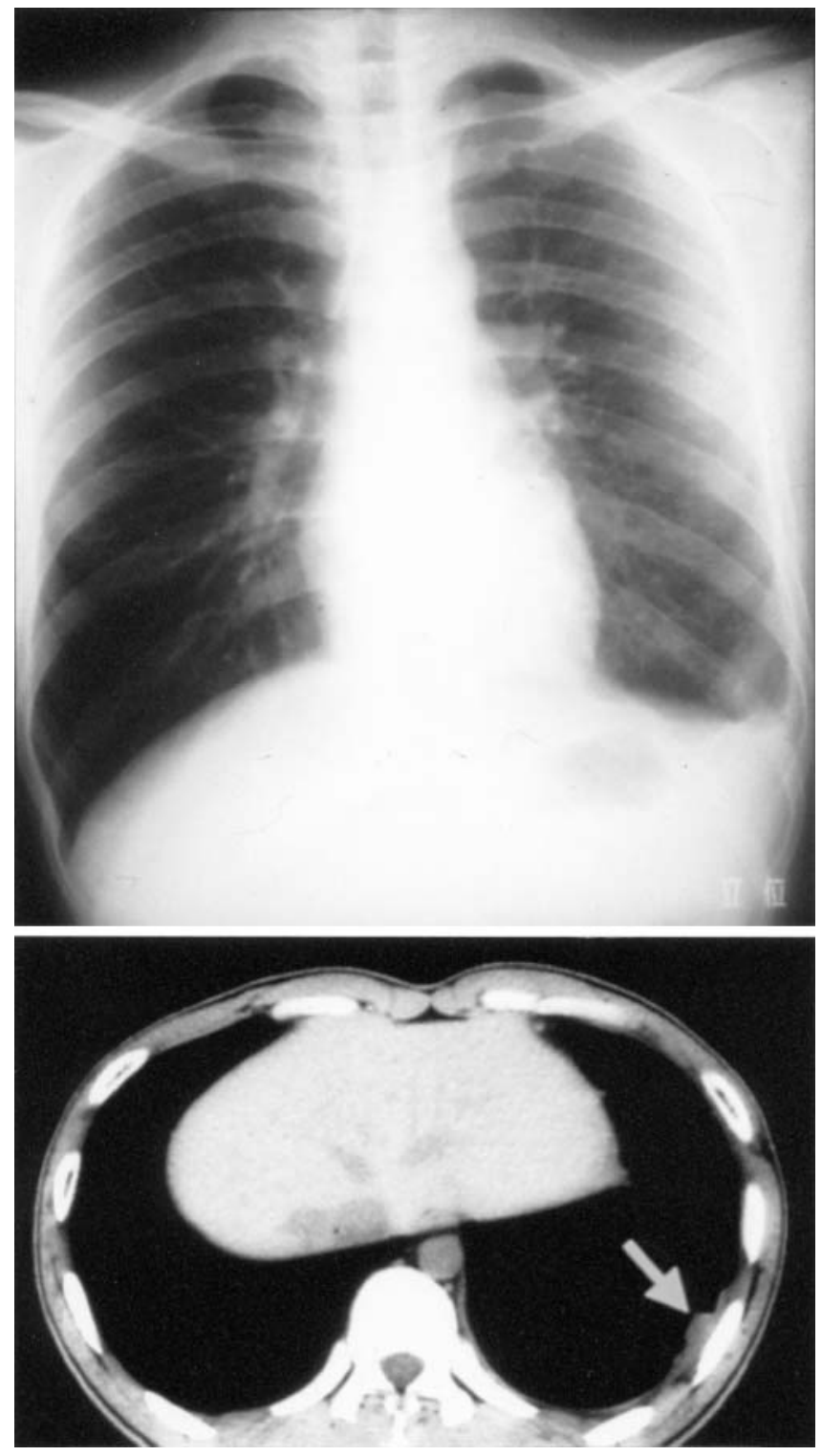

Figure 1. Chest X-ray and chest computed tomography films 2 weeks before admission showing dullness of left costophrenic angle and thickness of left pleura (arrow).

$400 \mathrm{mg} /$ day). Three weeks after the start of therapy, his chest pain disappeared. He was treated with fluconazole $(400 \mathrm{mg} /$ day) for three months. After the treatment, the abnormal shadow on his chest X-ray film almost disappeared (Fig. 3). However, the lymphocyte counts were still low and CD4 positive T lymphocyte counts were under $300 / \mu 1$ on 2 separate examinations (Fig. 4). He is in good health 3 years after admission. His CD4 positive T lymphocyte counts still remain low and the antibody for HIV is still negative. During the entire clinical course, he never received immunosuppressive drugs and he showed no evidence of malignant tumor.

\section{Flow cytometry analysis}

The expression of cell surface CD95 (Fas/APO-1) antigens was evaluated by flow-cytometry analysis. One hundred thousand cells were suspended in $50 \mu \mathrm{l}$ of cold PBS containing $0.1 \%$ sodium azide, $10 \mathrm{ng} / \mathrm{ml} \mathrm{BSA}$ and $20 \mu \mathrm{g} / \mathrm{ml}$ of human $\operatorname{IgG}$, incubated for 10 minutes on ice, and with mouse monoclonal anti-CD95 antibody and FITCconjugated CD4 antibody for an additional 15 minutes on ice. Cells were washed with PBS, and incubated with PEconjugated goat anti-mouse IgG for 15 minutes on ice. The cells were washed with PBS, and subsequently analyzed by flow cytometry using a FACScan (Becton Dickinson, San Jose CA, U.S.A.). Results were processed using the CellQuest software (Becton Dickson). In our patient, 80.5\% CD4 cells were positive for CD95 while $6.2 \pm 10.2 \%$ CD4 cells were positive for CD95 (Fig. 5).

Measurement of soluble Fas and Fas lignad in serum

We measured serum soluble Fas and Fas ligand concentrations in serum using an ELISA kit purchased from R\&D Systems, Minneapolis, MN.

\section{Discussion}

Cryptococcus neoformans infection rarely occurs in healthy individuals. Although if it does, pulmonary involvement commonly manifests with pulmonary nodules (5). Conversely, diffuse interstitial infiltrates, alveolar consolidation, ground glass shadow and mediastinal or hilar lymphadenopathy are most commonly seen in cases of immunocompromised hosts with a disease such as AIDS (1). Specifically, pleural abnormality is reported to be the least common pulmonary manifestation of Cryptococcus neoformans infection and its frequency was reported to be $0 / 10$ (6), 1/12 (7) and 3/14 (8). Some predisposing conditions of pleural cryptococcosis were previously reported such as malignant lymphoma, diabetes mellitus, renal failure, treatment with immunosuppressive drugs (9) and infection with HTLV-I (10), however, to the best of our knowledge, ICL has not been reported as a predisposing condition.

In 1992, the diagnostic criteria for ICL were defined by the Centers for Disease Control and Prevention (CDC) as follows (11): 1) CD4 positive T-lymphocyte depletion (absolute CD4 positive T lymphocyte level $<300 / \mu 1$ or $<20 \%$ of total lymphocytes on more than one trial), 2) no serological evidence of HIV infection, and 3) no defined immunodeficientive status or therapy associated with T-cell depletion. We believe that this case fulfilled the criteria for ICL for the following reasons: 1) The patient showed no evidence of HIV infection and had never received immunosuppressive drugs; 2) he suffered from an opportunistic infection (Cryptococcus neoformans); 3) the CD4 positive T lymphocyte count was below 300/ $\mu \mathrm{l}$ on more than 2 occasions and was still below 300/ $\mu 13$ years after admission.

ICL is a rare disease with an incidence of $0.25 \%$ among blood donors (12) and 1.5\% in HIV-seronegative homo- 


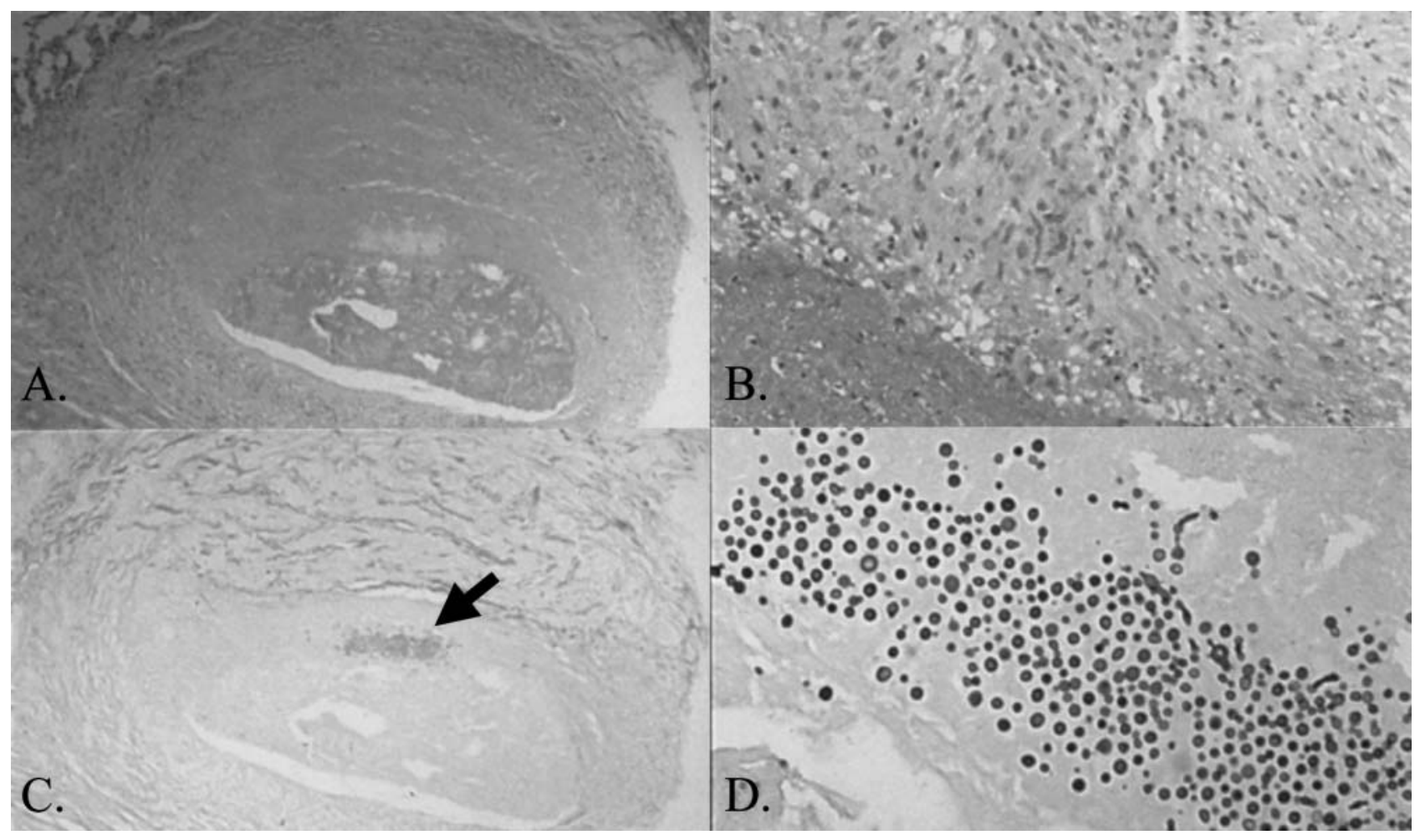

Figure 2. Hematoxylin-eosin staining of the biopsied specimen of pleura showing granuloma formation with infiltration of inflammatory cells (A: original manifestation $\times 150, B$ : original manifestation $\times 400$ ). And Grocott staining of the biopsied specimen showing well-encapsulated yeast forms characteristic of Cryptococcus neoformans (C: original manifestation $\times 150$, D: original manifestation $\times \mathbf{4 0 0}$ ). The arrow indicates yeast forms.

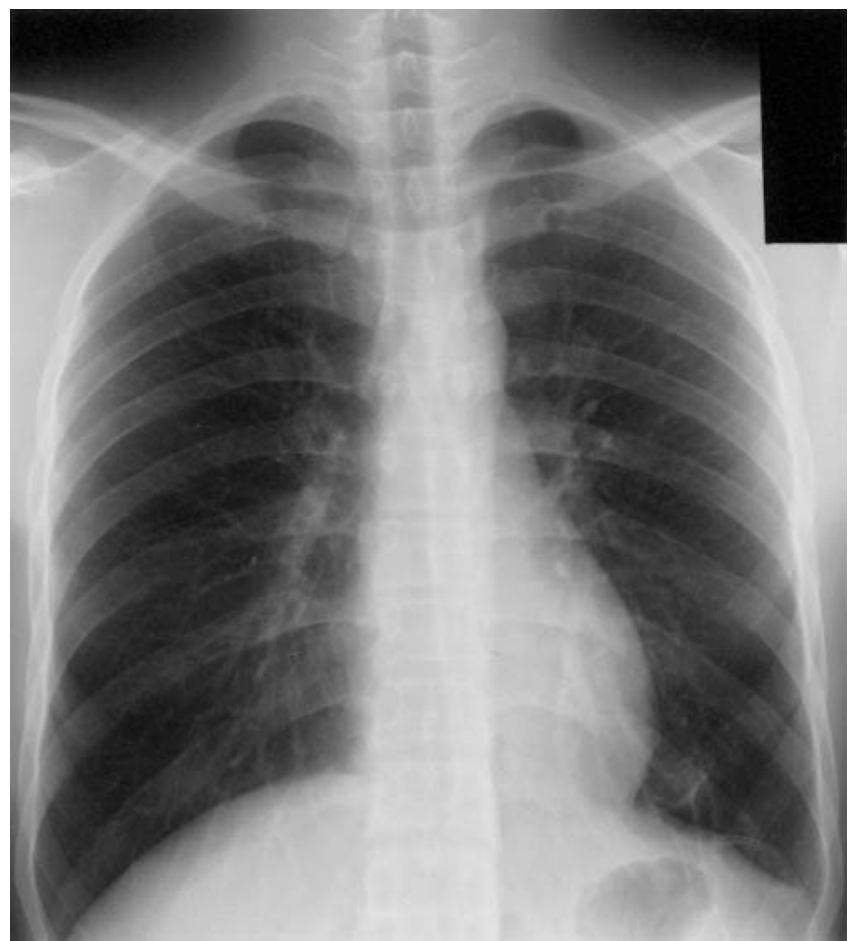

Figure 3. Chest X-ray film 3 months after the treatment with fluconazole.

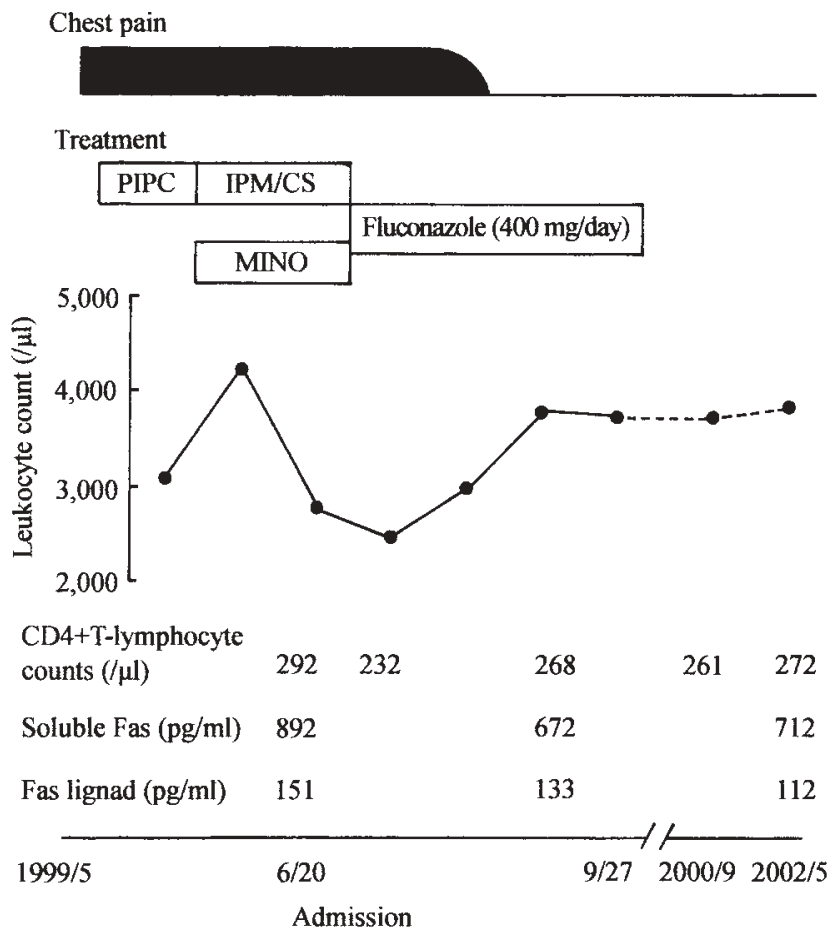

Figure 4. Clinical course of the present case. 

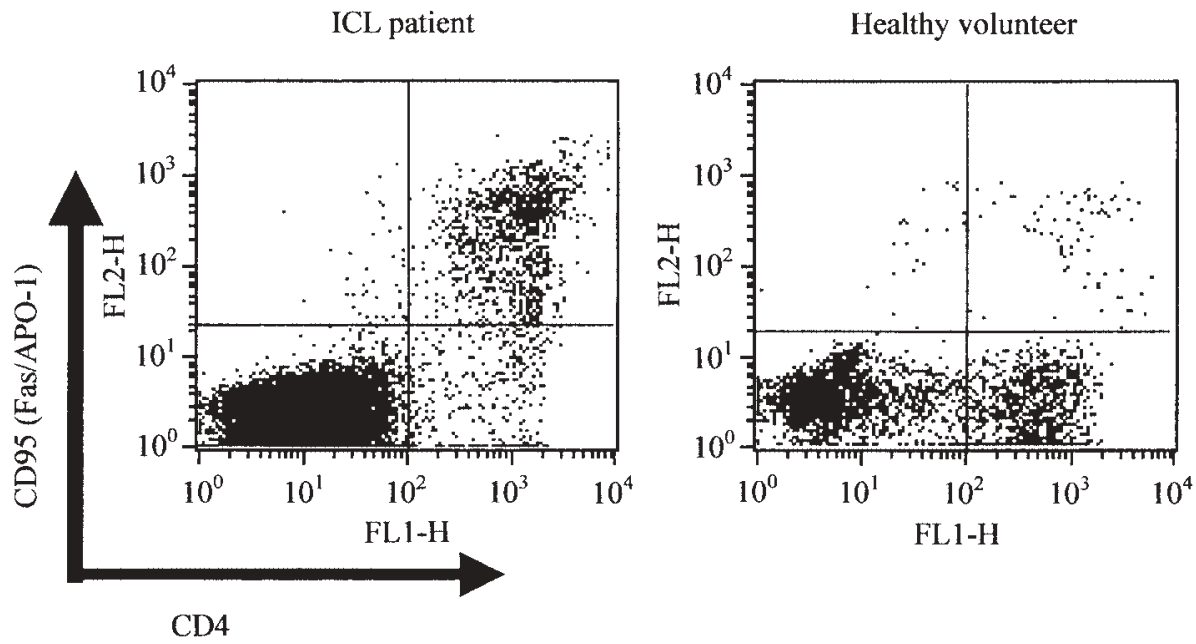

Figure 5. Results of flow cytometry analysis of the present case and one of healthy volunteers. The percentage of CD95 positive CD4 positive cell was higher $(80.5 \%$ of CD4 positive cells) than healthy volunteer $(6.2 \%$ of $\mathrm{CD} 4$ positive cells). This is the representative result of 3 different experiments.

sexual men (13). In Japan, only 19 cases have been reported and Mycobacterium tuberculosis is the most frequent pathogen followed by atypical mycobacterium (14-17) while Pneumocystis carinii or Cryptococcus neoformans are the common pathogens of ICL in other countries $(3,18)$. There are some reports of ICL cases with cryptococcus infection in the central nervous system and pulmonary parenchyma (19), however there are no reports of ICL cases with pleural cryptococcus infection as seen in the present case.

Granulomatous inflammation evoked by cryptococcus is uncommon and is not observed in immunosuppressed individuals (20). Granuloma formation indicates an intact cellmediated immunity resulting in localization of the disease $(20,21)$. In the present case, natural killer cell activity and lymphocyte blastogenesis against PHA were normal. These results indicate that our case had an intact cell-mediated immunity despite the low number of CD4 positive lymphocytes. This is an interesting point and we think this might explain why ICL cases do not have disseminated cryptococcus infection. Further accumulation of cases addressing this point is necessary to clarify the detailed immune mechanism in ICL.

Laurence et al reported a possible association of CD4 positive lymphocyte apoptosis with ICL (22) and Roger et al reported an ICL case with high CD95 (Fas/APO-1) (23). CD95 (Fas/APO-1) is a member of the tumor necrosis factor (TNF)/nerve growth factor superfamily that can directly transduce an apoptotic death signal on trimerization with Fas ligand (24). Therefore, to examine whether the present case shows high CD95 expression or not, we measured CD95 positive cells in peripheral blood mononuclear cells (PBMCs) of this patient and 8 healthy volunteers. Our case showed a higher percentage of CD95-positive CD4-positive lymphocytes than healthy volunteers. CD95 (Apo-1/Fas) is a member of the TNF/nerve growth factor superfamily that can directly transduce an apoptotic death signal on trimerization with Fas ligand (CD95L) or Fas-specific Abs $(25,26)$. Fas is expressed on the surface of various cell types, including $\mathrm{T}$ cells, B cells, and macrophages, as well as cells of the liver, spleen, lung, testis, heart, brain, and intestine (27, 28). Apoptosis provides one mechanism for the regulation of peripheral CD4 positive T-cell homeostasis. Recent studies suggested that T-cell apoptosis is associated with T-cell activation by either CD3 positive cross-linking, phorbol myristate acetate, or phytohemagglutinin $(25,26,29-32)$. This occurs through a MHC nonrestricted monocytedependent mechanism (33). The requirement for T-cell activation seems to be a common feature of monocyte-dependent apoptosis mediated by Fas-FasL interaction $(30,34,35)$. Laurence et al suggested that patients with ICL linked to clinical immune suppression have evidence for accelerated $\mathrm{T}$ cell apoptosis in vitro (22) and Roger et al reported an ICL case in which CD4 positive T lymphopenia was correlated with an overexpression of CD95 (Fas receptor) together with spontaneous and Fas-induced apoptosis (24). The result of the present patient was compatible with previous reports. Therefore, we propose the possibility that "primed" Fas positive CD4 positive lymphocytes of ICL patients may interact with activated monocytes that express FasL, resulting in apoptosis that leads to preferential deletion of CD4 positive $\mathrm{T}$ cells and immune dysfunction in ICL.

In summary, we report the first case of pleural cryptococcosis in association with ICL. ICL should be considered as one of the predisposing conditions of pleural cryptococcosis. CD95 (Fas/APO-1) may be associated with the CD4 positive T lymphocyte depletion in ICL; in this regard, 
further studies addressing this point may be necessary to clarify the pathogenesis of ICL.

Acknowledgements: We wish to thank Dr. Yoshimizu Koreeda, Dr. Kazutaka Nishitarumizu and Dr. Kentarou Machida (Third Department of Internal Medicine, Kagoshima University Faculty of Medicine). We also appreciate Mrs. Rumi Matsuyama (Third Department of Internal Medicine, Kagoshima University Faculty of Medicine) for her excellent help.

\section{References}

1) Kovacs JA, Kovacs AA, Polis M, et al. Cryptococcosis in the acquired immunodeficiency syndrome. Ann Intern Med 103: 533-538, 1985.

2) Newman TG, Soni A, Acaron S, Huang CT. Pleural cryptococcosis in the acquired immune deficiency syndrome. Chest 91: 459-461, 1987.

3) Soriano V, Hewlett I, Heredia A, et al. Idiopathic CD4+ T-lymphocytopenia. Lancet 340: 607-608, 1992.

4) Smith DK, Neal JJ, Holmberg SD. Unexplained opportunistic infections and CD4+ T-lymphocytopenia without HIV infection. An investigation of cases in the United States. The Centers for Disease Control Idiopathic CD4+ T-lymphocytopenia Task Force. N Engl J Med 328: 373-379, 1993.

5) Khoury MB, Godwin JD, Ravin CE, Gallis HA, Halvorsen RA, Putman CE. Thoracic cryptococcosis: immunologic competence and radiologic appearance. AJR Am J Roentgenol 142: 893-896, 1984.

6) Suster B, Akerman M, Orenstein M, Wax MR. Pulmonary manifestations of AIDS: review of 106 episodes. Radiology 161: 87-93, 1986.

7) Sider L, Westcott MA. Pulmonary manifestations of cryptococcosis in patients with AIDS: CT features. J Thorac Imaging 9: 78-84, 1994.

8) Friedman EP, Miller RF, Severn A, Williams IG, Shaw PJ. Cryptococcal pneumonia in patients with the acquired immunodeficiency syndrome. Clin Radiol 50: 756-760, 1995.

9) Young EJ, Hirsh DD, Fainstein V, Williams TW. Pleural effusions due to Cryptococcus neoformans: a review of the literature and report of two cases with cryptococcal antigen determinations. Am Rev Respir Dis 121: 743-747, 1980.

10) Taguchi H, Kotani S, Sugito S, Kobayashi M, Kubonishi I, Miyoshi I. Cryptococcal pleural effusion in an HTLV-I carrier with Waldenstroem's macroglobulinemia. Acta Med Okayama 46: 45-47, 1992.

11) Unexpected CD4+ T-lymphocyte depletion in persons without evident HIV infection - United Status. MMWR Recomm Rep 41: 541-545, 1992.

12) Busch MP, Valinsky JE, Paglieroni T, et al. Screening of blood donors for idiopathic CD4+ T-lymphocytopenia. Transfusion 34: 192-197, 1994.

13) Tindall B, Elford J, Sharkey T, Carr A, Kaldor J, Cooper DA. CD4+ lymphocytopenia in HIV-seronegative homosexual men. AIDS 7: 1272-1273, 1993.

14) Hirasaki $\mathrm{S}$, Koide N, Ogawa H, Tsuji T. Active intestinal tuberculosis with esophageal candidiasis due to idiopathic CD4(+) T-lymphocytopenia in an elderly woman. J Gastroenterol 35: 47-51, 2000.

15) Matsuyama W, Tsurukawa $T$, Iwami $F$, et al. Two cases of idiopathic CD4+ T-lymphocytopenia in elderly patients. Intern Med 37: 891-895, 1998.

16) Suzuki Y, Suzuki S, Numata M, et al. Acute respiratory failure due to miliary tuberculosis in a patient with idiopathic CD4+ T-lymphocytopaenia. Respir Med 92: 977-979, 1998.

17) Watanabe H, Inukai A, Doyu M, Sobue G. CNS cryptococcosis with idiopathic CD4+ T lymphocytopenia. Rinsho Shinkeigaku 40: 249253, 2000 (in Japanese).
18) Smith DK, Neal JJ, Holmberg SD. Unexplained opportunistic infections and CD4+ T-lymphocytopenia without HIV infection. An investigation of cases in the United States. The Centers for Disease Control Idiopathic CD4+ T-lymphocytopenia Task Force. N Engl J Med 328: 373-379, 1993.

19) Ho CL, Chang BC, Hsu GC, Wu CP. Pulmonary cryptococcoma with CD4 lymphocytopenia and meningitis in an HIV-negative patient. Respir Med 92: 120-122, 1998.

20) Baker RD, Haugen RK. Tissue changes and tissue diagnosis in cryptococcosis: a study of 26 cases. Am J Clin Pathol 25: 14-24, 1955.

21) Mohanty SK, Vaiphei K, Dutta U, Singh K. Granulomatous cryptococcal lymphadenitis in immunocompetent individuals: report of two cases. Histopathology 42: 96-97, 2003.

22) Laurence J, Mitra D, Steiner M, Lynch DH, Siegal FP, Staiano-Coico L. Apoptotic depletion of CD4+ T cells in idiopathic CD4+ T lymphocytopenia. J Clin Invest 97: 672-680, 1996.

23) Roger PM, Bernard-Pomier G, Counillon E, Breittmayer JP, Bernard A, Dellamonica P. Overexpression of Fas/CD95 and Fas-induced apoptosis in a patient with idiopathic CD4+ T lymphocytopenia. Clin Infect Dis 28: 1012-1016, 1999.

24) Fleck M, Zhou T, Tatsuta T, Yang P, Wang Z, Mountz JD. Fas/Fas ligand signaling during gestational $\mathrm{T}$ cell development. J Immunol 160: 3766-3775, 1998.

25) Itoh N, Yonehara S, Ishii A, et al. The polypeptide encoded by the cDNA for human cell surface antigen Fas can mediate apoptosis. Cell 66: 233-243, 1991.

26) Watanabe-Fukunaga R, Brannan $\mathrm{CI}$, Itoh $\mathrm{N}$, et al. The cDNA structure, expression, and chromosomal assignment of the mouse Fas antigen. J Immunol 148: 1274-1279, 1992.

27) Oehm A, Behrmann I, Falk W, et al. Purification and molecular cloning of the APO-1 cell surface antigen, a member of the tumor necrosis factor/nerve growth factor receptor superfamily. Sequence identity with the Fas antigen. J Biol Chem 267: 10709-10715, 1992.

28) Talmadge JE, Reed E, Ino K, et al. Rapid immunologic reconstitution following transplantation with mobilized peripheral blood stem cells as compared to bone marrow. Bone Marrow Transplant 19: 161-172, 1997.

29) Ageitos AG, Varney ML, Bierman PJ, Vose JM, Warkentin PI, Talmadge JE. Comparison of monocyte-dependent $\mathrm{T}$ cell inhibitory activity in GM-CSF vs G-CSF mobilized PSC products. Bone Marrow Transplant 23: 63-96, 1999.

30) Ino K, Singh RK, Talmadge JE. Monocytes from mobilized stem cells inhibit T cell function. J Leukoc Biol 61: 583-591, 1997.

31) Mielcarek M, Martin PJ, Torok-Storb B. Suppression of alloantigeninduced T-cell proliferation by CD14+ cells derived from granulocyte colony-stimulating factor-mobilized peripheral blood mononuclear cells. Blood 89: 1629-1634, 1997.

32) Talmadge JE, Reed EC, Kessinger A, et al. Immunologic attributes of cytokine mobilized peripheral blood stem cells and recovery following transplantation. Bone Marrow Transplant 17: 101-109, 1996.

33) Ageitos AG, Varney ML, Bierman PJ, Vose JM, Warkentin PI, Talmadge JE. Comparison of monocyte-dependent $\mathrm{T}$ cell inhibitory activity in GM-CSF vs G-CSF mobilized PSC products. Bone Marrow Transplant 23: 63-69, 1999.

34) Mills KC, Gross TG, Varney ML, et al. Immunologic phenotype and function in human bone marrow, blood stem cells and umbilical cord blood. Bone Marrow Transplant 18: 53-61, 1996.

35) Tanaka J, Mielcarek M, Torok-Storb B. Impaired induction of the CD28-responsive complex in granulocyte colony-stimulating factor mobilized CD4 T cells. Blood 91: 347-352, 1998. 